\title{
Digitization and Networking of Translators' Occupational Archives
}

\author{
Jiehai Liu \\ School of Languages and Cultures \\ Nanjing University of Information Science and Technology \\ Nanjing, China
}

\begin{abstract}
Under the background of big data and Internet era, the development of occupational files is facing both challenges and opportunities. In this essay, we firstly elaborate the necessity and feasibility of the digitization and networking of translator's occupational archives. Then, embroidering on the three elements, languages, genres, and expertise, we come up with and execute the digitization and networking of translator's occupational files, which coordinated with the principle of correlation and openness. The result must be of benefit to improve the professional image, confidence and competitive ability of translators.
\end{abstract}

Keywords-occupational archievs; digitization; netwroking; $e$ portfolio; transloator

\section{INTRODUCTION: OCCUPATIONAL ARCHIVES}

\section{A. Definition of Occupational Archives}

Generally speaking, archives (including records and files) are different forms of historical records with preservative values directly caused by all sorts of governmental, organizational and personal productions or social activities. There are three types of archives, namely, governmental, organizational and personal archives, and their formats can be in the forms of texts, multimedia, materials and so on. Besides, it can also be categorized into documentary, technological and special archives [1]. Occupational archives, often referred to as personal portfolio, are a kind of well-sorted and wellorganized documentary collections including one's occupational skills, occupational expectations, educational background, occupational attitudes, professional experience, relevant works and so on [2]. Normally, occupational archives are personal files and will be categorized by different types of industries.

\section{B. Features of Occupational Archives}

Compared with common files, occupational archives contain four features.

- Professionalism. Occupational archives will be sorted and organized based on one's industry, and the contents will reflect the features of the industry. For example, a teacher's occupational files will contain information of his educational background, academic works, teaching experience and so on, and these information carries distinctive features of the teaching

This research was funded by Humanities \& Social Sciences Foundation of China Ministry of Education (project ID: 15YJC740046). industry.

- Personalization. Occupational files are personal files and personalized files which contains the contents that will show the advantages and characteristics of the owners. Take a designer as an example. Apart from the normal information such as educational background and work experience, his outstanding works are the key contents, which will directly show his personalized occupational abilities.

- Display. Rather than being kept cryptically, the primary purpose of occupational files is to show to the public the work experience and professional skills of the owners.

- Marketing. The ultimate purpose of publishing occupational files is to establish cooperation or employment relationships with potential clients.

\section{THE NECESSITIES AND FEASIBILITIES OF DigitiZATION AND NETWORKING}

Translator is a general term for professionals who are engaged in translation, interpretation and localization. The occupational files of translators are collections of all kinds of documents in written or in other forms regarding the translators' professional skills, educational background, work experience and relevant works. According to the situation of the translation market in China, freelancers make up a large part of all [3]. They often submit their occupational files to their clients or companies for record in the form of a resume, because of which, those files are lack in continuous updates, let alone the digital and organizational management from the companies. As a result, digitization and networking are quite urgent for translators to manage their occupational files.

\section{A. Necessities}

- In the information age, it is an irreversible trend to digitize occupational files. The so-called digitization is a comprehensive technology for fast transfer and accurate processing by transferring signals of sound, light, electricity and magnet or information of voices, words and images into digital signals or codes with computer information processing technology [4]. Digitization of occupational files is to homogenize all the occupational information of different forms into digital ones so as to save, retrieve and spread them. 
China is currently in the wave of globalization. As a result, international communication is becoming increasingly frequent, and the vigorous developing translation market leads to the continuous increase of freelancers. Under such circumstances, the digitization of translators' occupational files, on one hand, will help translation companies scientifically manage the translators' occupational file, and on the other hand, will be good for the freelancers to show and promote themselves.

- The digitization of occupational files is necessary for translators to realize self-marketing and improve their career confidence. There are hundreds of thousands of translators in China for now. In order to be outstanding in the fierce competition, translators must choose carefully and organize scientifically the contents in their occupational files including work experience, translation works, field of training, professional skills and so on. By using digitization technology to homogenize the information, and with the help of network media, they can show, promote and market themselves to attract more clients. Thus, their career confidence could be improved.

- The occupational files are demanded urgently to be digitized for enhancing the client's trust on translators. In order to get a better knowledge of the translators' professionalism and abilities, clients will go through some key information in the translators' occupational files including their work experience, fields of training, representative works and so on. Based on the knowledge from the occupational files, the clients will put more trust on the translators, which will be beneficial to facilitate business and achieve a win-win situation.

\section{B. Feasibilities}

- The mature file system and the favorable market atmosphere. Since the reform and opening up, the gradual improvement and perfection of the national file system have provided a great macro-environment for the development of personal files and occupational files. The National Archives of China has been promoting digitization for a long time and common netizens nowadays can retrieve lots of public files on the "National Archives website". Apart from the translation industry, there's also an increasing market demand for occupational files in various industries. Nowadays, the occupational files have become an important method for teachers, lawyers, doctors and other professionals to communicate with their clients and also a reliable basis for their clients to do evaluation. Similarly, it is also an imperative trend for professional translators to construct and promote the digitization of occupational files.

- The maturity and improvement of digital technology. In the post-PC era, PC and smart phones have been highly prevailed all round the world [5]. Common digitization methods for files, such as word processing, scanning, OCR (Optical Character Recognition), sound recording, video recording and so on, can basically be operated via PC and smart phones. The maturity and popularization of digitization technology have lowered the threshold, making it faster and highly efficient to digitize files.

- The development of the internet technology has made it more convenient and faster for storing and retrieving information. The rapid development of the internet technology, such as FTP (super-big files, especially), file sharing, cloud storage, IM (Instant Messaging), social media and so on, has made it faster and more convenient for information storage and retrieval. Suppose, there is an interpreted video of $1 \mathrm{~GB}$. Ten years ago, it could only be recorded and stored in a CD, and delivered by post. But now, with online cloud storage or super-big file sharing technology, it can be stored and transferred within a very short time.

\section{HOW TO REALIZE DIGITIZATION AND NETWORKING}

\section{A. The Choices and Organizations of Contents for the Occupational Files}

Before digitizing the occupational files, the translators first need to think what to choose and how to organize the contents. Owing to the features of the translation field, the occupational files will include but not be limited to the following contents [6]: brief career description, career expectations, personal motto, educational background, field of training, languages, blog, work resume, achievements and rewards, translated works, essays and works, etc. In practice, many translation institutions will catalogue the translators' occupational files according to the content structure above. However, from the clients' point of view, the contents above are comprehensive but not pertinent enough. What attracts the clients are usually the translation service itself and the translators' competence. To stand out from the fierce competition in the industry, translators must organize the contents carefully so as to target the right clients.

According to the international common practice, in order to target the right clients, translators must put emphasis on the following three aspects [7]:

- Languages. Translators can sort the languages in order based on their proficiency or translation experience. For example, English, Japanese, French. Besides, interpreters can also list some dialects such as Cantonese, Hokkien dialect, Shanghai dialect and so on as subsidiary language abilities in the files.

- Types. Apart from written translation (literature and non-literature) and interpretation, common translation types also include subtitle translation and software localization and some other types. To compete in the mature and subdivided translation market, translators must edit and sort all the translation types they expert in, pertinently publish and display to their clients.

- Fields. On top of literary translation and business interpretation, the translation field has expanded to various aspects of social production and social living including literature, finance and economics, politics, 
exhibition, tourism, medicine and engineering, and there are even possibilities of further subdivision. As a result, when organizing and managing the occupational files, translators can prepare several versions of occupational files for targeting different translation fields.

Moreover, samples of translation works are also necessary. When preparing the occupational files, translators can attach relevant translation works based on the three aspects mentioned above, and also pay attention to the following tips. First, the samples should represent the translator's high competence and should be better displayed parallelly with the original texts. Second, the length of the samples should be modest. 200 to 300 words are enough for clients to know about the quality of the translation, so there's no need to attach the whole translation as a sample. Third, the contents should not contain classified or private information. No matter how short the translation sample is, it should never contain classified information or let out clients' privacy. Fourth, should attach the translators' information in the samples. By this means, translators can not only leave a deep impression on the clients, but also allow to be contacted by the clients.

\section{B. Digitization of the Occupational Files}

There exist both connections and differences between digitization and networking of occupational files. First, the purpose of digitization is to store and transfer the information conveniently, and make a way for transferring and sharing occupational files. Second, networking is the main purpose of digitizing occupational files. By sharing occupational files on the internet, translators can attract their target clients more easily and conveniently. Third, digitization emphasizes the technology and its usage, and networking focuses on the means and effects of communications. They will have connections in software application. Speaking of the means of digitizing occupational files, they can be divided into two aspects - offline methods and online methods.

- Offline methods include not only processing technologies such as word processing, scanning, recording, photography, videoing, but also storage and retrieval technologies such as electrical file making software, electrical file management system, file retrieval database (or server). For example, a translator has collected his years' occupational files and primarily sorted all those paper and digital files out based on the three aspects "languages, translation types and fields" mentioned above. Then, the translator uses his smartphone to scan and OCR those paper files, sort and save those texts and pictures to the PC. After that, the translator needs to assemble and archive the digitized files with part of the files stored in the PC so that his clients can retrieve or share them online. If a translation company employs lots of translators, they can repeat the steps above and store all translators' occupational files to the server, managing and retrieving them with file retrieval devices.

- Online methods mean the server-based and web-based software or applications that can realize digitization and that functionally replace offline devices for file storage and retrieval. There are several types of such software or applications: online SaaS (such as Digication), OSS (such as Mahara), and secondary development \& application based on OSS (such applications developed from WordPress). With these online applications, translators are able to organize and manage those digitized occupational files systematically based on the "three aspects" mentioned above. Compared with offline methods, online applications are more inclined to massively and transregionally collect, sort and retrieve files, which is suitable for large translation companies and undergraduate teaching management for translation majors.

\section{Networking of the Occupational Files}

The digitized occupational files will eventually be spread and shared via network. Only by sharing the occupational files online can the translators accurately target and attract their clients in the subdivided translation market. Normally, there are several methods for networking:

- Common web pages. They can be personal web pages or company web pages and usually will be static pages displaying translators' occupational files. Such web pages are easy to make, convenient to maintain and update, but they are not suitable for mass production and management.

- Personal website. It has become quite convenient to make a personal website based on different CMS. By using CMS such as WordPress and Joomla, a translator can build up a personalized website for his occupational files and share it via network. The advantages of a personal website are quite obvious as the website is personalized, the interface is beautiful and it can leave a deep impression on the clients. But, the website hosting will cost extra expenses.

- Personal social media. Based on personal web pages, many translators continuously update valuable information on their personal social media (Weibo, WeChat, Facebook, etc.). This method allows translators to spread information rapidly as well as get good interactive effects. But it will also consume lots of time for maintenance.

- Professional social websites. Such social websites, LinkedIn especially, have attracted hundreds of millions of professionals on them. These social websites have well-processed SEO, plenty of page views, high clients' attention and good interactive effects. However, the file system or resume templates are not suitable for translators, or to say, they are not able to show the characteristics of translation professionals in the field.

As is seen above, SEO is vitally important in all online promotion. Technically, the effective SEO of CMS and professional social websites can favorably lead the potential clients to the target files. So, for translators with highly personalized demands, a professional SEO processing will 
increase the page views and clients' attention of their personal websites.

\section{CONCLUSION}

Digitization and networking of translators' occupational files are a general trend in the age of big data and internet. It reflects the rule of relevancy when translators digitize the contents of their occupational files based on the three aspects "languages, translation types and translation fields", while the purposes and technologies translators use for networking of their occupational files embody the rule of openness. Based on the two rules, the digitized and networked occupational files will definitely promote the translators' professional images and career confidence as well as their competence in the translation field. We believe that. in the future, more economical and user-friendly methods will be developed for digitization and networking, and that service institutions and companies will appear for professional technical fields, and that the mature and developed social network will be further subdivided for different industries.

\section{REFERENCES}

[1] The Engcyclopeida of China. Huaxia Press. 1990, p. 434.

[2] Salend, S J. "Creating your own professional portfolio". Intervention in School and Clinic, 2001, vol. 36, issue 4, pp. 195-201.

[3] Min, Min., et. al. "A surveyof Translations Services in China”. Yingyu Jiaoshi, 2015, vol. 15, issue 6, pp. 34-38

[4] Wang, Xueping. "On the Practice and Development Strategy of Digitized Construction of Archives in China". Danganxue Tongxun. 2011, vol. 6, pp.54-57.

[5] Li, Xuemei. "Problems and Countermeasures in Archival Utilization in Post-PC Era". Lantai World, 2015, vol. 29, pp. 82-84.

[6] Reyes, Marcela. "Branding Yourself: Create a Professional Portfolio" [EB/OL].http://www.atanet.org/chronicle/feature_article_january2014.p hp.

[7] Martelli, Alessandra. "How to create an effective portfolio for your translation business" [EB/OL]. http://www.mtmtranslations.com/englishblog/how-to-create-an-effective-portfolio-for-your-translation-business. 